\title{
Evaluating the Concept of Choice in Healthcare
}

\author{
Yusrita ZoLKeFLI
}

Submitted: 21 Aug 2017

Accepted: 1 Oct 2017

PAPRSB Institute of Health Sciences, Universiti Brunei Darussalam, Jalan

Online: 29 Dec 2017

Tungku Link Gadong BE1410, Brunei Darussalam

To cite this article: Zolkefli Y. Evaluating the concept of choice in healthcare. Malays J Med Sci. 2017;24(6):92-96. https://doi.org/10.21315/mjms2017.24.6.11

To link to this article: https://doi.org/10.21315/mjms2017.24.6.11

\begin{abstract}
Choice is what we all want, as most would say. There is a growing cognisance that patients can and should play an important role in deciding their own care, in defining optimal care, and in improving healthcare delivery. Popular concepts such as patient-centred care, patient empowerment, and patients as partners, shared decision making, and informed choice illustrate the emancipation of patient. The paper describes that choice is not necessarily a good thing in health care; however, that does not rebut the significance of choice. In order to support the overall argument, the paper focuses on why patient choice is important, and in each discussion, this is disputed with counter-arguments to demonstrate that in fact, to an extent, choice is not necessarily a good thing in healthcare.
\end{abstract}

Keywords: choice, ethics, autonomy, healthcare, obligation

\section{Introduction}

Today, despite of the meaningful intention of promoting choice to patients, it is not always possible to do this, especially if we look at the implications of such choice from different perspectives. It is suggested that there is always probable conflict between allowing greater choice for consumers and changing healthcare policy that is directed more towards standardised healthcare provision (1). Healthcare professionals in general, are expected to offer choice, simply because it will promote and enhance autonomy, but also it is the right thing to do. However, choice itself, comes with responsibility, that is one which is accountable for their choice and decision-making, and arguably, one choice usually impacts on other people particularly when resources are scarce. So, this brings us to the question of, is there a special moral duty and obligation for health professionals to always offer a choice to patients? Or, are there situations where some degree of limited choice may be justifiable, in order to promote the principles of beneficence, nonmaleficence and justice?

\section{Choice and Respect for Autonomy}

Autonomy has emerged as one of the most frequently referenced concepts in recent healthcare practice. Choice is tied to the notion of individual autonomy or freedom, a concept that has emerged largely in ethical theories of the good. For example, regarding any treatment offered to patients, it is believed that giving them choices will not just enhance their autonomy but also better inform them about their health conditions and the available treatments (1). Arguably, there is a fundamental obligation to ensure that patients have the right to choose as well as the right to accept or to decline information (2). Furthermore, Beauchamp and Childress contend that, in some cases, health professionals are obliged to increase the options available to patients, whereby many autonomous actions could not occur without the health professionals and health organisation cooperating to make these options available. At the same time, the ability to exercise choice is highly valued in many cultures as an expression of individual identity and autonomy. 
Health care practice encompasses situations in which choices are given and decisions are made, offering frequent opportunities for patients to exercise choice and for practitioners to respect these choices. Hence, respecting patients' choices seems to be a way of recognising their moral status as individuals and their capacity for self-determination (3). Nonetheless, respect for autonomy is not an absolute principle within healthcare in general. This is evident from the nature of autonomy itself as well as the implications of 'choice' from the consequentialist approach. First, we need to know that respect for autonomy has only prima facie standing and competing moral considerations can sometimes override it. For example, if our choices jeopardise public health, potentially harm others, or require a scarce resource for which no funds are available, others can justifiably curb our exercising of autonomy. It is further postulated that, to be genuinely autonomous, we are required to take seriously the social implications of our choices. Whilst there may be occasions when we feel that others do not determine our choices and our choices cannot benefit from discussion with them, this in fact happens very seldom. Of course, it is possible for a person alone to come to a valid moral choice. But placing too much emphasis on the promotion of individual patient choice, particularly when such choices are actually made alone, carries the risk that we might forget either the interests of others or the wider public interest (3).

The most prominent example is that of vaccine safety. Increasing doubts about vaccination appear to stem from conflicting scientific evidence over possible (minor) side effects, and yet it is highly effective. A qualitative study reports that Dutch parents refused all or some of the vaccinations in the National Immunisation Program. Their refusal to vaccinate was established to reflect manifold factors, including family lifestyle; perceptions about the child's body and immune system; perceived risks of disease, vaccine efficacy, and side effects; perceived advantages of experiencing the disease; prior negative experience with vaccination; and the social environment (4). Other studies indicate that doubts surrounding vaccine safety have resulted in a drop in the number of children being vaccinated and in an increase in outbreaks of measles. Hence, it has been asserted that providing more choice is likely to lead to lower levels of protection and more infections. In other words, when parents decide not to have their children vaccinated, further harm is potentially possible. The Institute of Medicine of the National Academies (5) reported that some parents appears to dismiss the well-documented benefits of vaccines and fear potential side effects which lead them not vaccinating their children. In a recent review, it was reported the association between vaccine delay or refusal, and the epidemiology of measles. The study shows that substantial proportion of the measles cases in the United States among individuals who were unvaccinated (6).

In reality, healthcare systems cannot provide everything that each individual patient could want. Arguably, it is possible to act nonmaleficently towards all people at all times, but it is generally not possible to act beneficently towards all people. Failing to act nonmaleficently toward a party is prima facie immoral, but failing to act beneficently toward a party is very often not immoral (2). Furthermore, the fact that there is conflict between the duties of care that health professionals hold limits patient's choice and autonomy. Patients' wishes as well as the goals of medicine define the ethical obligations of health professionals (2). Health professionals have no obligation to perform beyond or contradictorily to the goals of medicine even when patients request that they do so. Hence, patients have no right to demand that health professionals provide medical care that is contraindicated, for instance, unnecessary surgery or unorthodox treatments such as odd drug regimens, and should not demand that health professionals do anything illegal or unethical (7).

In practice, there are three main reasons why a patient may be refused his or her treatment of choice. First of all, the doctor regards the treatment as worse than no treatment at all, and doctors are not obliged to give treatments which they think will be detrimental to their patients; secondly, what the patient wants is futile, that is, the treatment is ineffective; and thirdly, what the patient wants, whilst effective for him or her, is not costeffective for the health service or the opposite situation may hold. Based on the third reason, let us suppose that there is a new and expensive drug for a particular condition. Whilst the expensive treatment may be effective, it may not be cost-effective. The cost, for example, per year of life saved, may far surpass what the health service can generally afford. The health authority may quite reasonably decide not to 
purchase this drug at all or to only do so for a specified group of patients for whom the drug is more cost-effective (8). In the opposite situation, suppose that what the patient wants is cheaper than the treatment offered but significantly less effective and, therefore, less cost-effective. Giving the patient what he or she wants rather than standard treatment would save money but would lead to less overall benefit. The extreme of this situation entails a patient choosing a futile but cheap treatment. Again, this situation raises the issue of justice (9). If the patient was paying for the drug him or herself, there may be no good reason to refuse such treatment. But, where the cost of the drug comes from taxes, then by giving this patient what he or she wants, will be to deny another patient a quality of treatment that would otherwise be possible. Hence, this patient's choice is in fact, another patient's lack of choice. However, the demands of justice require that patients should not have such choices (9). Justice may demand that one patient is not given what is individually optimal because another patient has a greater moral prerogative to a scarce resource. Thus, if the hospital's intensive care unit is full and no patient is stable enough to be transferred from it, the relatively stable patient may be sent to a more distant intensive care unit.

Another question is "To what extent are such patients' choices real?" Arguably, even autonomous people with self-governing capacities sometimes fail to govern themselves in the making of particular choices because of temporary constraints caused by illness or depression or because of ignorance, coercion, or other conditions that restrict their options (10). Hence, choice may in itself benefit the patient, but it may disadvantage him or her as well. For example, a mother who refuses to go for antenatal screening may not just be putting her health and the pregnancy at risk, it may also be difficult for health professionals to carry out their moral duties of doing goods (concept of beneficence), that is to benefit the mother through antenatal care. Furthermore, it is notable that, when provided with information and the opportunity for greater involvement in making decisions, consumers generally become warier of the treatments offered and make more conservative choices. In cases of serious illness, such as myocardial infarction or meningococcal disease, the choices are explicit: one may accept the treatment or risk dying. Given the desire to remain alive, there is, in effect, no choice for the patient (11). Therefore, although there is a compelling argument for promoting choice to patients as a means of upholding respect for patient autonomy, strong evidence is emerging that such a notion is not always possible, particularly when the quality of choice and its impact on others are, to an extent, disputed.

\section{Choice and Psychological Implications}

Giving patients choices has been linked to their satisfaction. It has also been suggested that patient preferences are essential to good clinical care because the patient's cooperation and satisfaction reflect the degree to which medical intervention fulfils his or her choices, values, and needs. This cooperation in decision-making results in greater trust in the health professional-patient relationship (7). Furthermore, individuals are likely to receive greater satisfaction from the goods and services they purchase if they choose them. It is plausible that individuals would appreciate particular goods better if they picked them out of a set of alternatives than if someone else assigned the goods to them (12).

More participation of patients is seen as leading to better adherence to advice and treatment and, thus, to better health outcomes (1). Besides, patients' choices are psychologically significant because the ability to have choices, express those choices, and have others respect them is central to a sense of personal worth. This is important because the patient, already threatened by an illness, may have a principal need for some sense of control. When patient choice is ignored or devalued, patients are likely to distrust and, perhaps, disregard health professionals' recommendations, which may later result in the jeopardising of the effectiveness of the treatment (7). On the other hand, patient choice is also important because its expression may lead to the discovery of other factors such as fear or unfamiliar beliefs that health professionals should consider when dealing with patients.

Meanwhile, we cannot deny that some people sometimes make the wrong choices. Thus, it follows that some forms of paternalism are justified. In ethical terms, paternalism represents the opinion that beneficence is a higher value than autonomy; a situation can occur in which paternalistic behaviour is ethically permissible (7). Moreover, sometimes too many choices 
essentially result in the patient not being able to make a decision, whereby having to choose may risk stressing the patient further. A good example is the question of which hospital to go to. It is not possible for patients to judge whether hospital or consultant A is better than hospital or consultant B and by how much if they do not have the necessary information. In addition, too much information can be as debilitating as too little (13). Choice does not depend only on having information, as it also relies on the skill of understanding and choosing between options, whose probable consequences cannot be measured or even known (14). The knowledge, that they might be making the wrong decision, exposes patients to additional stress.

Furthermore, some patients simply refuse to choose for themselves and are happy about that! Some ask the doctor, "But what would you do, doctor?" One interpretation of respecting patient autonomy argues that the doctor should do exactly what the patient says. Hence, in this type of situation, the doctor should make the decision without involving the patient (8). Respecting the patient's choice implies, in this view, respecting his or her choice not to be involved in treatment decisions. Therefore, it is important to be aware that some patients may not want the responsibility, or burden, of decision-making and it would be inappropriate to offer these choices to patients in every situation. It is desirable that health professionals collect as much information about a particular patient's lifestyle and preferences as they can and then recommend the action they think most suits that patient (15). Health professionals also need to be more aware that an elderly woman, for instance, who refuses treatment to which she is entitled because she does not want to be a 'burden' may exemplify individual choice, which is erroneous in the opposite sense (3). Therefore, arguably, a strict no-paternalism policy will tend to produce good outcomes for prudent individuals who are skilled at making and executing personal decisions and less beneficial outcomes for individuals whose prudential skills are poor. On average the imprudent and bad choosers will be living worse lives. Even if a strict no-paternalism happened to be utilitymaximising, establishing some paternalism might be better for worse-off people, and required by fairness norms, especially if one thinks that prudence is often non-blameable (16).

\section{Conclusion}

Is it ever justified that choice is not necessarily a good thing in health care. Can limited choice be justified if it saves a human life or a community? It can be seen, from the arguments presented, that choice is thought of as an intrinsically good thing; and that people value choice in itself. However, this is not necessarily the case, as the autonomy and rights to choose can be overridden by the principles of beneficence, nonmaleficence and justice, as well as the fact that health professionals are not to give treatment unnecessarily. Similarly, we cannot reject the fact that providing choices to patients can be of benefit to patients, family and health professionals, yet, that benefit is not always 'good' for some who decided not to choose it. On psychological implications, choices may create satisfaction for some and many may have troubles in having to choose; we do indeed hear the saying: too much of something is not good and yet too little of something is also not good; hence, moderation is always best. Therefore, as much as patients are eager and desire for such choices, one has to remember that, choice comes with a cost, and it is a colossal one; that offering everybody a greater degree of control over what they receive will create winners and losers. Nevertheless, having considered the arguments regarding choice and its impact on healthcare in general, perhaps limited choice is more appropriate and acceptable than numerous choices. In other words, addressing the needs of an individual on a one-to-one basis will ultimately benefit or disadvantage the individual or society as a whole. Thus, without discounting the significance of a choice itself, choice is not necessarily a good thing in healthcare.

\section{Correspondence}

Dr Yusrita Zolkefli

Lecturer (Health Care Ethics)

MSc Health Care Ethics (University of Liverpool), PhD

Nursing Studies (The University of Edinburgh)

PAPRSB Institute of Health Sciences,

Universiti Brunei Darussalam, Brunei.

Tel: + 6732460922

Fax: +6732461081

E-mail: yusrita.zolkefli@ubd.edu.bn 


\section{References}

1. Elwyn G, Edwards A, Thompson R. Shared decision making in health care: achieving evidence-based patient choice. Oxford: Oxford University Press; 2016. https://doi.org/10.1093/ acprof:oso/9780198723448.001.0001

2. Beauchamp TL, Childress JF. Principles of biomedical ethics. 7th ed. New York: Oxford University Press; 2013.

3. Parker M. The ethics of evidence-based patient choice. Health Expectations. 2001;4(2):87-91. https://doi.org/10.1046/j.1369-6513.2001.00137.x

4. Harmsen IA, Mollema L, Ruiter R, Paulussen T, de Melker HE, Kok G. Why parents refuse childhood vaccination: a qualitative study using online focus groups. BMC Public Health. 2013;13:1183. https://doi.org/10.1186/1471-245813-1183

5. Institute of Medicine of the National Academies. The childhood immunization schedule and safety stakeholder concerns, scientific evidence, and future studies. Washington, DC: The National Academics Press; 2013. Available at: http://www. nationalacademies.org [Accessed February 3, 2017]. https://doi.org/https://doi.org/10.17226/ 13563

6. Phadke VK, Bednarczyk RA, Salmon DA, Omer SB. Association between vaccine refusal and vaccine-preventable diseases in the United States. A Review of Measles and Pertussis. The Journal of the American Medical Association (JAMA). 2016;315(11):1149-1158. https://doi. org/10.1001/jama.2016.1353

7. Jonsen AR, Siegler M, Winslade WJ. Clinical ethics. A practical approach to ethical decisions in clinical medicine. 8th ed. New York: McGrawHill; 2015.
8. Hope T, Savulescu J, Hendrick J. Medical ethics and law: the core curriculum. 2nd ed. London, UK: Churchill Livingstone; 2008.

9. Ashcroft E, Dawson A, Draper H, McMillan J, editors. Principles of health care ethics. 2nd ed. New Jersey: Wiley; 2007.

10. Seedhouse D. Ethics, the heart of health care. 3 rd ed. Chichester: John Wiley and Sons; 2009.

11. Rogers WA. Evidence-based medicine in practice: limiting or facilitating patient choice? Health Expectations. 2002;5(2):95-103. https://doi. org/10.1046/j.1369-6513.2002.00168.x

12. Rice $\mathrm{T}$. Individual autonomy and state involvement in health care. Journal of Medical Ethics. 2001;27:240-244. http://dx.doi.org/10. $1136 / \mathrm{jme} .27 .4 .240$

13. Bate P, Robert G. Choice: more can mean less. British Medical Journal. 2005;331:1488-1489. https://doi.org/10.1136/bmj.331.7531.1488

14. Hastie R, Dawes R. Rational choice in an uncertain world: the psychology of decision making. London: Sage; 2010.

15. Steer PJ. So what's so new about patient choice? British Medical Journal. 2006;332:981. https:// doi.org/10.1136/bmj.332.7547.981

16. Richard, A. Paternalism. In: Craig E, editor. Routledge Encyclopaedia of Philosophy. London: Routledge; 1998. Available at: http://www.rep. routledge.com 